\title{
A Computed Tomographic Study of Umbilical Anatomy: The Relationship between Umbilical Thickness and Diameter
}

\author{
Un Estudio de Tomografía Computadorizada de la Anatomía Umbilical: \\ La Relación entre Grosor y Diámetro Umbilical
}

\author{
Maru Kim**** \& Seong-Taek Oh$^{* *}$
}

KIM, M. \& OH, S. T. A computed tomographic study of umbilical anatomy: The relationship between umbilical thickness and diameter. Int. J. Morphol., 33(3):1060-1064, 2015.

SUMMARY: Laparoscopic surgeries were first introduced in the 1980s. More recently, similar techniques such as natural orifice transluminal endoscopic surgery and other advanced transumbilical surgeries have been developed. With all of these surgical advances, basic information about the umbilicus is lacking. This study evaluated the relationship between umbilical diameter and thickness, as well as the underlying vessels, in order to develop a simple means of assessing umbilical anatomy. We retroactively reviewed 842 computed tomography images that included the umbilicus. Umbilical thickness, diameter, type of vessel located beneath the umbilicus, depth to the vessel, and other parameters were measured. Age and sex were noted, and their relationship was analyzed as it pertains to the umbilical anatomy. Average umbilical thickness and diameter were $8.2 \mathrm{~mm}$ and $3.5 \mathrm{~mm}$, respectively. Vessels directly under the umbilicus were located on average $60.0 \mathrm{~mm}$ from the umbilicus. The most common vessels detected were the aorta and the right common iliac artery. A wider umbilical diameter was correlated with a thinner umbilicus. As natural orifice transluminal endoscopic surgery is relatively new, further studies regarding umbilical anatomy and clinical correlation are warranted. However, this report brings to light the importance of basic umbilical anatomy, and that these characteristics should be taken into account during the laparoscopic entry procedure.

KEY WORDS: Umbilicus; Anatomy; Laparoscopy.

\section{INTRODUCTION}

In the past, great incisions were the symbol of a great surgeon. This paradigm has changed with the introduction of laparoscopic surgeries described in the 1980s. Since then, these initial studies have been followed by myriad advances (Litynski, 1999; Semm, 1983). Outstanding exploration of the abdominal cavity coupled with reduced pain, hospital stays, recovery time, and surgical-site infection, and better cosmetics make it a preferred method of surgery in many cases (Nguyen et al., 2004; Chung et al., 1999; Champault et al., 2008; Lee et al. 2013).

A more recent advance in laparoscopic surgery is natural orifice transluminal endoscopic surgery (NOTES) (Kalloo et al., 2004). In most instances of NOTES, the endoscope is passed through a natural orifice rather than an incision. As such, NOTES is considered less invasive and scarless (Lee et al., 2012; Hong et al., 2009; Qiu et al., 2011). Transumbilical single incision surgery where a single incision is made at the navel was also introduced as scarless surgery. One concern with transumbilical incision surgery is determining how deep to dissect. The umbilicus, or navel, is a scar where the umbilical cord was attached during fetal development. In some patients, the tissue underlying the umbilicus is thin and amenable to incision. Conversely, other patients have very narrow umbilici and deep underlying tissue. Given that there is no rapid method to determine the depth of tissue beneath the umbilicus, we sought to assess whether there is a correlation between umbilical diameter and thickness. This study evaluated the relationship between these two parameters of the umbilicus in order to develop a simple means of assessing umbilical anatomy.

This pilot study was performed in order to better understand the umbilical anatomy as it relates to laparoscopic surgery. Vessels located beneath the umbilicus were analyzed. Despite its many benefits, especially during entry, laparoscopic surgery is associated with serious complications such as gastrointestinal tract and vascular injuries (Liu et

\footnotetext{
* Department of Surgery, Armed Forces Goyang Hospital, Goyang-si, Gyeonggi-do, Korea.

** Department of Surgery, College of Medicine, The Catholic University of Korea, Seoul, Korea.
} 
al., 2009; Ahmad et al., 2007; Krishnakumar \& Tambe, 2009). Vascular injury is a major cause of death from laparoscopic surgery, with a reported mortality rate of $15 \%$ (Krishnakumar \& Tambe). To reduce the risk of these complications, many types of entry techniques have been evaluated. Even so, information on the umbilicus, a typical entry site for these procedures, is lacking. Therefore, the type of vessel located beneath the umbilicus and depth to the vessel were assessed.

\section{MATERIAL AND METHOD}

Study design. This study was a retrospective analysis of computed tomography (CT) scans that included the umbilicus. The institutional review board at the Armed Forces Medical Command approved this study and informed consent was waived.

Patients. From January 1, 2010 to December 31, 2010, we identified 861 patients who had undergone $\mathrm{CT}$ that included the umbilicus. Of these patients, 19 were excluded from analysis owing to one of the following reasons: previous operation via the umbilicus, pathologic lesion at the umbilicus including umbilical hernia or fascial defect, radiologic reports that influence abdominal structure like ascites and scoliosis, or the position during the CT scan obscured the aorta or other vessels under the umbilicus. Patients who underwent a repeat CT scan within 3 months were also excluded. Also because the present study was performed in a military population, only limited females were included.

CT imaging. CT examination was performed with a 16channel multidetector scanner (BrightSpeed Elite; GE Healthcare, Milwaukee, WI, USA). All images were displayed on a picture archiving and communication system (PACS) (Centricity Enterprise Web 3.0.10, GE Medical Systems, Milwaukee, WI, USA). Measurements were taken using unenhanced axial images. However, for identifying vessels directly beneath the umbilicus, enhanced images were used. Measurements were obtained in millimeters and rounded to the nearest thousandth.

Method of measurement . Umbilical thickness was measured as the shortest length between the exterior of the skin and the surface of the peritoneum using axial CTimaging on PACS. If the peritoneal margin was unclear, it was measured at the point between the medial borders of both rectus abdominis muscles. The tissue depth recorded was the point at which the umbilicus was thinnest. In cases of asymmetrical umbilici, meaning the skin margins were vague, the deepest distinguishable point was used to measure the depth, and $2 \mathrm{~mm}$ above the deepest layer of umbilical skin, transverse lengths between both sides of the umbilicus were measured to get umbilical diameters.

The depth of the skin and subcutaneous fat layer were combined and defined as "skin thickness" in this study. The skin thickness was defined as the depth between the exterior of the skin and the superior side of the rectus sheath. Muscle thickness was defined as the depth between the superior and inferior border of the rectus abdominis fascia. For both muscle and skin, the thickest measurement was documented. Cavity diameter was defined as the longest transverse length of the peritoneal cavity. Likewise, abdominal diameter was defined as the longest transverse length of the abdomen. All parameters were checked on the same image for each patient at the point where the umbilicus was thinnest (Fig. 1).

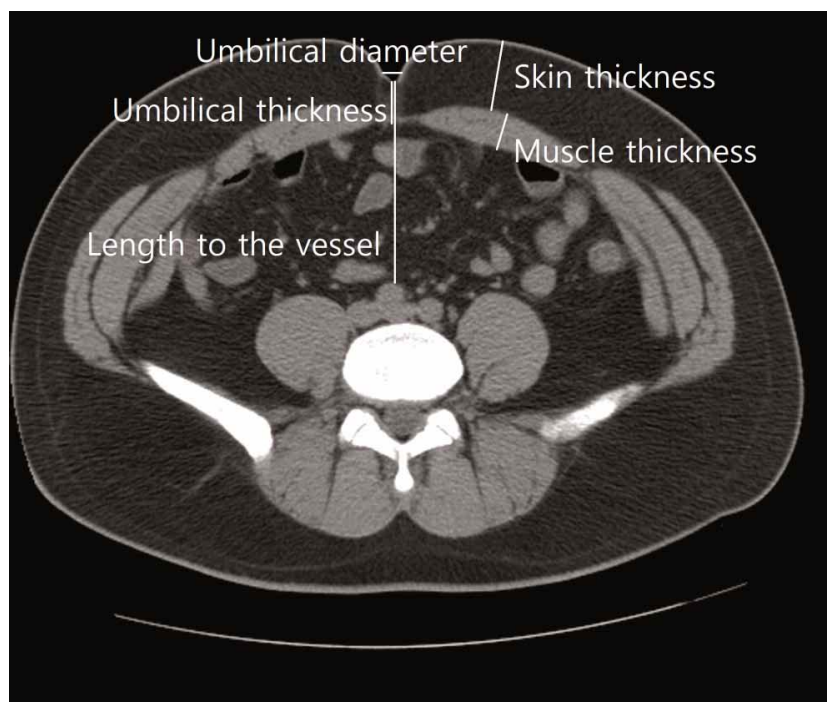

Fig. 1. Tissue depth was measured using axial CT imaging on PACS at the point that the umbilicus was thinnest. Umbilical thickness was measured as the shortest length between the exterior of skin and the surface of the peritoneum. If the peritoneal margin was unclear, it was measured at the point between the medial borders of both rectus abdominis muscles, and $2 \mathrm{~mm}$ above the deepest layer of umbilical skin. Transverse lengths between both sides of the umbilicus were measured as umbilical diameters. Depth to the vessels was measured from the deepest portion of the umbilical skin. The vessels are generally located on a vertical axis directly beneath the deepest layer of umbilical skin and have diameters greater than $5 \mathrm{~mm}$. In this case, the RCIA was identified.

Additional measurements for the depth to vessels were determined from the deepest layer of skin beneath the umbilicus. The vessels are generally located on a vertical axis directly beneath the deepest layer of umbilical skin and have diameters larger than $5 \mathrm{~mm}$ (those less than $5 \mathrm{~mm}$ were not included in this study). Branches of the superior 
mesenteric artery and vein (SMA and SMV) and inferior mesenteric artery and vein (IMA and IMV) were the main vessel. The common iliac artery and vein (CIA and CIV) were defined distal to bifurcation; bifurcating areas were assigned to the aorta and inferior vena cava (IVC), respectively. If the vertical line from the lowest umbilical layer of skin was located between the aorta and IVC, the point nearest to a vessel from the vertical line was used to measure the depth to the vessel.

Statistical analysis. Mean, standard deviation, and range of each parameter were analyzed. Differences between sexes were analyzed using the independent sample t test. One-way ANOVA was used to compare the sex of the patients to the type of vessel located directly beneath the umbilicus. Parameters that could influence umbilical thickness and diameter were analyzed using Spearman's correlation analysis. Multivariate analysis was performed via partial correlation between umbilical thickness and diameter. Other factors were adjusted, and the correlation coefficient between umbilical thickness and diameter was analyzed. All statistical analyses were performed using SPSS software (Version 17.0, SPSS INC., Chicago, IL). $\mathrm{P}<0.05$ was considered significant.

\section{RESULTS}

Features of the umbilici. A total of $842 \mathrm{CT}$ images were analyzed. Features of the umbilici are shown in Table I. The average umbilical thickness and diameter were $8.2 \pm 4.9 \mathrm{~mm}$ and $3.5 \pm 2.4 \mathrm{~mm}$, respectively.

Table I. Features of the umbilici.

\begin{tabular}{lcc}
\hline & Mean \pm SD & Range \\
\hline Umbilical thickness & $8.2 \pm 4.9$ & $1.6-38.0$ \\
Umbilical diameter & $3.5 \pm 2.4$ & $0.9-15.6$ \\
Length to the vessel & $60.0 \pm 19.0$ & $12.5-131.5$ \\
Skin thickness & $19.9 \pm 12.3$ & $3.3-225.8$ \\
Muscle thickness & $15.1 \pm 5.1$ & $7.0-145.6$ \\
Cavity diameter & $220.0 \pm 19.2$ & $48.64-287.9$ \\
Abdominal diameter & $296.1 \pm 30.0$ & $35.9-418.8$ \\
Age & $29.6 \pm 12.1$ & $5-71$ \\
\hline
\end{tabular}

All dimensions are in mm except age, which is in years. $\mathrm{SD}=$ Standard deviation.
Table II. Anatomic features of umbilici and other parameter analyzed by sex.

\begin{tabular}{lccc}
\hline & $\begin{array}{c}\text { Male } \\
(\mathbf{n}=\mathbf{8 0 9})\end{array}$ & $\begin{array}{c}\text { Female } \\
(\mathbf{n = 3 3 )}\end{array}$ & $\boldsymbol{p}$ value \\
\hline Umbilical thickness & $8.1 \pm 4.8$ & $10.6 \pm 4.9$ & 0.004 \\
Umbilical diameter & $3.5 \pm 2.4$ & $2.4 \pm 1.2$ & $<0.001$ \\
Length to the vessel & $60.3 \pm 18.8$ & $53.8 \pm 21.1$ & 0.053 \\
Skin thickness & $19.7 \pm 2.4$ & $25.2 \pm 7.5$ & 0.011 \\
Muscle thickness & $15.2 \pm 5.2$ & $11.7 \pm 1.9$ & $<0.001$ \\
Cavity diameter & $220.2 \pm 19.2$ & $215.6 \pm 18.9$ & 0.171 \\
Abdominal diameter & $296.2 \pm 29.9$ & $296.0 \pm 31.3$ & 0.972 \\
Age & $29.4 \pm 12.0$ & $36.3 \pm 14.4$ & 0.016 \\
\hline All dimensions are in mm except age, which is in years. Data are presented as Mean \pm \\
Standard deviation.
\end{tabular}

Anatomic features of the umbilici and other parameters analyzed by sex. Umbilical thickness and diameter were compared between males and females (Table II). On average, the umbilici of male patients were thinner and wider compared to those of female. Moreover, the integument was thicker in female patients while the muscle layer was thicker in male patients.

Relationship between umbilical thickness and diameter. Larger umbilical diameters were associated with thinner umbilici. Additionally, umbilici with larger diameters tended to have thicker skin and a wider abdominal diameter (Table III). Factors relating to umbilical diameter were also analyzed (Table IV). Thicker umbilici and skin thickness were correlated with a narrower umbilical diameter.

Table III. Bivariate correlation* between umbilical thickness and other parameters.

\begin{tabular}{lcc}
\hline Factor & $\begin{array}{c}\text { Correlation } \\
\text { coefficient }\end{array}$ & $\boldsymbol{p}$ value \\
\hline Umbilical diameter & -0.401 & $<0.001$ \\
Length to the vessel & 0.335 & $<0.001$ \\
Skin thickness & 0.647 & $<0.001$ \\
Muscle thickness & 0.083 & 0.016 \\
Cavity diameter & 0.235 & $<0.001$ \\
Abdominal diameter & 0.479 & $<0.001$ \\
Age & -0.101 & 0.766 \\
\hline *Spearman's correlation. & &
\end{tabular}

Table IV. Bivariate correlation* between umbilical diameter and other parameters.

\begin{tabular}{lcc}
\hline Factor & $\begin{array}{c}\text { Correlation } \\
\text { coefficient }\end{array}$ & p value \\
\hline Umbilical thickness & -0.401 & $<0.001$ \\
Length to the vessel & -0.039 & 0.262 \\
Skin thickness & -0.341 & $<0.001$ \\
Muscle thickness & 0.004 & 0.903 \\
Cavity diameter & -0.068 & $<0.001$ \\
Abdominal diameter & -0.184 & $<0.001$ \\
Age & -0.056 & 0.104 \\
\hline *Spearman's correlation. & &
\end{tabular}


Table V. Partial correlation between umbilical thickness and umbilical diameter.

\begin{tabular}{ccc}
\hline & Umbilical thickness & Umbilical diameter \\
\hline Umbilical thickness & 1 & $-0.310(P<0.001)$ \\
Umbilical diameter & $-0.310(P<0.001)$ & 1 \\
\hline
\end{tabular}

Correlation coefficients were presented.

Table VI. Assessment of the type of vessel located beneath the umbilicus and depth to the vessel.

\begin{tabular}{lc}
\hline Vessel type (n, \%) & Length to the vessel \\
\hline Aorta $(400,47.5 \%)$ & $61.1 \pm 18.8$ \\
IVC $(150,17.8 \%)$ & $65.4 \pm 19.1$ \\
RCIA $(161,19.1 \%)$ & $58.1 \pm 17.7$ \\
RCIV $(3,0.4 \%)$ & $75.4 \pm 31.1$ \\
LCIA $(33,3.9 \%)$ & $65.8 \pm 19.5$ \\
LCIV $(23,2.7 \%)$ & $58.7 \pm 16.5$ \\
SMA $(2,0.2 \%)$ & $35.9 \pm 20.5$ \\
SMV $(56,6.7 \%)$ & $44.3 \pm 13.0$ \\
IMA (7, 0.8\%) & $41.6 \pm 11.4$ \\
IMV (7, 0.8\%) & $58.9 \pm 19.0$ \\
$p$ value & $<0.001$ \\
\hline All dimensions are in mm. Data are presented as Mean \\
\pm Standard deviation. IVC= inferior vena cava; RCIA= \\
right common iliac artery; RCIV= right common iliac \\
vein; LCIA= left common iliac artery; LCIV= left \\
common iliac vein; SMA= superior mesenteric artery; \\
SMV= superior mesenteric vein; IMA= inferior \\
mesenteric artery; IMV= inferior mesenteric vein
\end{tabular}

To evaluate the correlation between umbilical thickness and diameter without the effects of confounding factors, partial correlation analysis was performed (Table V). All factors except for of umbilical thickness and diameter were adjusted. Wider umbilical diameters remained correlated with thinner umbilici.

Assessment of the vessels located beneath the umbilicus and depth to the vessels. As depicted in Table VI, the aorta was the most common vessel found beneath the umbilicus, followed by the right common iliac artery (RCIA). These vessels were located $61.1 \pm 18.8 \mathrm{~mm}$ and $58.1 \pm 17.7 \mathrm{~mm}$ from the umbilicus, respectively. The SMA and IMA were uncommon vessels, however, generally closer to the umbilicus.

\section{DISCUSSION}

The present study was performed to evaluate the anatomy of the umbilicus. Basic information regarding this topic is needed so as to make better-informed surgical decisions when performing transumbilical entry procedures. As such, we retroactively analyzed CT scans from 842 patients.
Estimating the average umbilical thickness and depth to vessels based on umbilical diameter would greatly aid surgeons in deciding where and how deep to dissect. The aorta and RCIA are commonly found directly beneath the umbilicus. Even though the SMA and IMA (larger than $5 \mathrm{~mm}$ ) are rarely found in this location, our study did note them. Given this information, surgeons should take care to check for branches of the SMA and IMA as they dissect through the umbilicus.

While other imaging tools such as ultrasonography (US) offer certain advantages, for this work, the benefits of CT outweigh the detail of US. Typically, umbilical anatomy is not assessed during routine abdominal US. Moreover, CT scans can yield information without diagnostic interpretation, making it a more objective tool. CT imaging also lends itself to large scale, retrospective studies, such as this one. Another advantage of CT versus US is that vessels, like the aorta, are not always visible on US (Koda et al., 2007). An alternative to imaging techniques is to use a cadaver. While cadaver studies may produce more detail, statistical power is lacking as access to cadavers is limited. Fathi et al. (2012) reported on umbilical anatomy using cadavers but that study only enrolled 24 subjects. Conversely, a large number of cases can be analyzed via $\mathrm{CT}$ and acquiring statistical power is simpler.

Our study has the limitation that it was performed at a single military hospital. Although civilian patients were enrolled, nearly all of the patients in this study were young, male soldiers. As a result, there was a significant difference between the average age of the male and female patients. However, there was no statistical difference when age was factored into the measurements of the umbilical thickness and diameter. Also lacking was additional morphological data, such as height and weight. These factors may play a role in umbilical anatomy and would be of interest for follow-up studies. Overall, additional investigation is warranted as a more stratified population may produce different results, or better confirm the data we present here. Also evaluation about correlation of CT measurements with actual operative measurements is required.

Of great interest is to determine if there is a relationship between umbilical anatomy and clinical results following these surgeries. There are some reports that indicate transumbilical surgery led to greater pain than conventional laparoscopic surgery (Kim et al., 2012; Jung et al., 2011; Phillips et al., 2012). Umbilical anatomy might influence pain following transumbilical surgery. Narrow and thick umbilici require a wider dissection area for entry and may lead to greater injury during operation than wide and thin umbilici. Given the results presented here and the supporting empirical evidence, the use of transumbilical surgery should be evaluated in terms of umbilicus anatomy. 
In conclusion, a wider umbilical diameter was correlated with a thinner umbilicus. The average umbilical thickness, diameter and other features were analyzed. The most common vessels detected beneath the umbilicus were the aorta and RCIA. Surgeons should take basic umbilical anatomy into account during the laparoscopic entry procedure. Further studies regarding umbilical anatomy and clinical correlation are warranted.

KIM, M. \& OH, S. T. Un estudio de tomografía computadorizada de la anatomía umbilical: La relación entre grosor y diámetro umbilical. Int. J. Morphol., 33(3):1060-1064, 2015.

RESUMEN: Las cirugías laparoscópicas se introdujeron en la década de 1980. Recientemente, se han desarrollado técnicas similares, tales como cirugía endoscópica transluminal por orificios naturales y otras cirugías transumbilicales avanzadas. Con todos estos avances quirúrgicos, es insuficiente la información básica sobre el ombligo. Este estudio evaluó la relación entre el diámetro y el espesor umbilical, así como los vasos subyacentes, a fin de desarrollar un medio simple de evaluar la anatomía umbilical. Se revisaron retroactivamente 842 imágenes de tomografía computarizada que incluían el ombligo. Se midió espesor umbilical, diámetro, el tipo de vaso situado bajo del ombligo, y la profundidad junto a otros parámetros. Se observaron edad y sexo, y se analizó su relación en lo que respecta a la anatomía umbilical. Espesor umbilical medio y el diámetro eran de $8,2 \mathrm{~mm}$ y $3,5 \mathrm{~mm}$, respectivamente. Vasos directamente bajo el ombligo se localizaron en promedio $60,0 \mathrm{~mm}$ del ombligo. Los vasos más comunes detectados fueron la aorta y la arteria ilíaca común derecha. Un diámetro más amplio umbilical se correlacionó con un ombligo más delgado. Como en los orificios naturales la cirugía endoscópica transluminal es relativamente nueva, se justifican más estudios en relación con la anatomía umbilical y su correlación clínica. Sin embargo, este informe pone de manifiesto la importancia de la anatomía básica umbilical, y que estas características se deben tener en cuenta durante el procedimiento de entrada laparoscópica.

\section{PALABRAS CLAVE Umbilicus; Anatomía; Laparoscopía.}

\section{REFERENCES}

Ahmad, G.; Duffy, J. M. \& Watson, A. J. Laparoscopic entry techniques and complications. Int. J. Gynaecol. Obstet., 99(1):52-5, 2007.

Champault, A.; Polliand, C.; Mendes da Costa, P. \& Champault, G. Laparoscopic appendectomies: retrospective study of 2074 cases. Surg. Laparosc. Endosc. Percutan. Tech., 18(2):168-72, 2008.

Chung, R. S.; Rowland, D. Y.; Li, P. \& Diaz, J. A meta-analysis of randomized controlled trials of laparoscopic versus conventional appendectomy. Am. J. Surg., 177(3):250-6, 1999.

Fathi, A. H.; Soltanian, H. \& Saber, A.A. Surgical anatomy and morphologic variations of umbilical structures. Am. Surg., 78(5):540-4, 2012.

Hong, T. H.; You, Y. K. \& Lee, K. H. Transumbilical single-port laparoscopic cholecystectomy : scarless cholecystectomy. Surg. Endosc., 23(6):13937, 2009.

Jung, Y. W.; Lee, M.; Yim, G. W.; Lee, S. H.; Paek, J. H.; Kwon, H. Y.; Nam, E. J.; Kim, S. W. \& Kim, Y. T. A randomized prospective study of singleport and four-port approaches for hysterectomy in terms of postoperative pain. Surg. Endosc., 25(8):2462-9, 2011.
Kalloo, A. N.; Singh, V. K.; Jagannath, S. B.; Niiyama, H.; Hill, S. L.; Vaughn, C. A.; Magee, C. A. \& Kantsevoy, S. V. Flexible transgastric peritoneoscopy: a novel approach to diagnostic and therapeutic interventions in the peritoneal cavity. Gastrointest. Endosc., 60(1):114$7,2004$.

Kim, H. O.; Yoo, C. H.; Lee, S. R.; Son, B. H.; Park, Y. L.; Shin, J. H.; Kim, H. \& Han, W. K. Pain after laparoscopic appendectomy: a comparison of transumbilical single-port and conventional laparoscopic surgery. $J$. Korean Surg. Soc., 82(3):172-8, 2012.

Koda, M.; Senda, M.; Kamba, M.; Kimura, K. \& Murawaki, Y. Sonographic subcutaneous and visceral fat indices represent the distribution of body fat volume. Abdom. Imaging, 32(3):387-92, 2007.

Krishnakumar, S. \& Tambe, P. Entry complications in laparoscopic surgery. $J$. Gynecol. Endosc. Surg., 1(1):4-11, 2009.

Lee, J. S.; Choi, Y. I.; Lim, S. H. \& Hong, T. H. Transumbilical single port laparoscopic appendectomy using basic equipment: a comparison with the three ports method. J. Korean Surg. Soc., 83(4):212-7, 2012.

Lee, J. H.; Lee, C. M.; Son, S. Y.; Ahn, S. H.; Park do, J. \& Kim, H. H. Laparoscopic versus open gastrectomy for gastric cancer: long-term oncologic results. Surgery, 155(1):154-64, 2013.

Litynski, G. S. Profiles in laparoscopy: Mouret, Dubois, and Perissat: the laparoscopic breakthrough in Europe (1987-1988). J. S. L. S., 3(2):1637, 1999.

Liu, H. F.; Chen, X. \& Liu, Y. A multi-center study of a modified open trocar first-puncture approach in 17350 patients for laparoscopic entry. Chin. Med. J. (Engl.), 122(22):2733-6, 2009.

Nguyen, N. T.; Zainabadi, K.; Mavandadi, S.; Paya, M.; Stevens, C. M.; Root, J. \& Wilson, S. E. Trends in utilization and outcomes of laparoscopic versus open appendectomy. Am. J. Surg., 188(6):813-20, 2004.

Phillips, M. S.; Marks, J. M.; Roberts, K.; Tacchino, R.; Onders, R.; DeNoto, G.; Rivas, H.; Islam, A.; Soper, N.; Gecelter, G.; Rubach, E.; Paraskeva, P. \& Shah, S. Intermediate results of a prospective randomized controlled trial of traditional four-port laparoscopic cholecystectomy versus singleincision laparoscopic cholecystectomy. Surg. Endosc., 26(5):1296-303, 2012.

Qiu, Z.; Sun, J.; Pu, Y.; Jiang, T.; Cao, J. \& Wu, W. Learning curve of transumbilical single incision laparoscopic cholecystectomy (SILS): a preliminary study of 80 selected patients with benign gallbladder diseases. World J. Surg., 35(9):2092-101, 2011.

Semm, K. Endoscopic appendectomy. Endoscopy, 15(2):59-64, 1983.

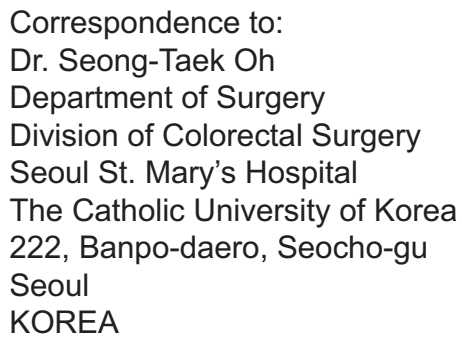

Received: 14-03-2015

Accepted: 20-07-2015

Email: stoh@catholic.ac.kr 